\title{
GESTÃO PÚBLICA NO BRASIL: DESAFIOS E PERSPECTIVAS
}

\section{ARTIGO ORIGINAL}

WOLTER, Alzirene Pontoni ${ }^{1}$

VELHO, Altemir da Silva ${ }^{2}$

WOLTER, Alzirene Pontoni. VELHO, Altemir da Silva. Gestão Pública no Brasil:

Desafios e perspectivas. Revista Científica Multidisciplinar Núcleo do Conhecimento. Ano 05, Ed. 02, Vol. 02, pp. 18-27. Fevereiro de 2020. ISSN: 24480959 Link de acesso: https://www.nucleodoconhecimento.com.br/administracao/gestao-publica$\underline{\text { no-brasil }}$

\section{RESUMO}

A finalidade deste estudo é fazer uma reflexão sobre a gestão pública e sugerir estratégias que venham a otimizar o desempenho da gestão pública em benefício da sociedade brasileira. Para tal, foi realizada uma retrospectiva histórica assim como uma análise de sua evolução no tempo. A abordagem utilizada baseou-se na pesquisa bibliográfica e nas informações obtidas por meios eletrônicos a partir da internet. Destaca-se, nesse artigo, as ações adotadas pelo governo para inovar na gestão pública com foco na eficiência e transparência, analisando-se, portanto, tendências e desafios da gestão. $\mathrm{O}$ estudo sugere o desenvolvimento de políticas voltadas à motivação e qualificação da mão de obra estatal e propõe o investimento em ferramentas gerenciais visando promover a modernização, agilidade e eficiência da administração pública.

${ }^{1}$ Pós-Graduação em Gestão Pública pela Faculdade de Administração, Ciências, Educação e Letras - FACEL; Bacharel em Ciências Contábeis pela Faculdade de Ciências Administrativas e Contábeis Costa Braga.

${ }^{2}$ Graduação em Administração de Empresas. Mestrado em Engenharia de Produção. 
Palavras-chave: Eficiência, Ferramentas Gerenciais, Gestão Pública, inovação, transparência.

\section{INTRODUÇÃO}

O intuito deste estudo é fazer uma retrospectiva da evolução da gestão pública no Brasil, analisando seu desenvolvimento até os dias atuais, seus desafios e perspectivas futuras. O questionamento proposto por esta pesquisa concentra-se nos desafios enfrentados pela gestão pública contemporânea, tais como adaptar-se às mudanças apresentadas pelo mundo atual, melhorar, continuamente, os serviços oferecidos pelo Estado e implementar políticas públicas eficientes que atendam às expectativas e bem-estar dos clientes (sociedade). Dessa forma, o presente estudo procura responder a seguinte pergunta: quais são os desafios e perspectivas da Gestão Púbica no Brasil? Ser capaz de adaptar-se às mudanças do mundo contemporâneo, melhorar de forma gradativa e contínua os serviços estatais e implementar políticas públicas que atendam as expectativas dos cidadãos são os desafios enfrentados pela Gestão Pública Brasileira.

É necessário, para superar os desafios acima citados, a utilização de várias ferramentas, são elas: orçamento participativo, qualificação profissional do servidor público, modernização da mão-de-obra do Estado, motivação dos servidores públicos, profissionalização da gestão pública e a utilização de ferramentas da tecnologia da informação. Observa-se que existe um esforço governamental voltado para o aprimoramento da gestão pública. A implementação da transparência e a integração sistêmica das ouvidorias responsáveis pela interlocução Estado/ Sociedade é um exemplo desse esforço. Nesse contexto, o objetivo geral deste trabalho consiste em explanar os desafios e as perspectivas da gestão pública no panorama brasileiro.

Para alcançar este objetivo geral foram definidos os seguintes objetivos específicos: analisar o desenvolvimento da gestão pública no Brasil; apontar alguns dos atuais desafios enfrentados pela gestão publica brasileira; enunciar algumas ferramentas de gestão e propor a utilização de ferramentas focadas na melhoria da gestão pública no Brasil. Assim sendo, este estudo tem como base a pesquisa bibliográfica e a coleta 
de dados a partir da internet. Possui natureza predominantemente descritiva e dedutiva, tendo sido utilizado, subsidiariamente, a técnica de análise de conteúdo.

\section{FUNDAMENTAÇÃO TEÓRICA}

\subsection{DESENVOLVIMENTO DA GESTÃO PÚBLICA NO BRASIL}

A política adotada até 1930 era a do clientelismo. Tal política privilegiava a elite ruralista mineira e paulista, principal eixo de comando político na república velha. Garantia, à elite, privilégios sociais e econômicos, como, também, a impunidade diante da corrupção e demais benefícios. Com a revolução de 1930, o sulista Getúlio Vargas assumiu o poder e adotou práticas inovadoras para a gestão pública brasileira. O Estado ganhou um novo perfil: o de desenvolvimentista e de articulador na consolidação de uma nova identidade nacional. (FREITAS, DACORSO, 2014). Em 1979, durante a ditadura militar, apenas uma política foi desenvolvida em relação à inovação dos processos públicos: a criação do Ministério da Desburocratização. A principal prática inovadora foi a de ressaltar que o contribuinte não é um súdito do Estado, mas um cliente com direito à boa prestação de serviços públicos (FREITAS, DACORSO, 2014).

A década de 80 foi marcada por reformas orientadas para a democratização das políticas públicas. Com a promulgação da Constituição Federal em 1988, inaugurouse um ciclo descentralizador. Os recursos antes administrados pela União foram transferidos para os Estados, Distrito Federal e Municípios. Isto proporcionou mais autonomia aos entes governamentais. Paralelamente, a sociedade civil mobilizou-se e passou a envolver-se com as ações do poder público de forma mais ativa, especialmente nas áreas de saúde, educação e assistência social. Tal posicionamento levou a criação de novos espaços públicos de interação e negociação. Nesse contexto, novos conceitos de gestão foram difundidos junto à máquina estatal.

A disponibilidade do governo em ouvir os apelos da sociedade culminou na inovação institucional, a saber, a promulgação da Lei № 12.527, de 18 de novembro de 2011. 
Esta lei, denominada Lei de Acesso à Informação, disciplina os procedimentos a serem seguidos pela União, Estados, Distrito Federal e Municípios, a fim de garantir acesso da população às informações públicas (FREITAS, DACORSO, 2014). Posteriormente, buscou-se estreitar a comunicação entre sociedade/governo a partir do orçamento participativo. Segundo Freitas e Dacorso (2014), a inserção das práticas de administração privada na gestão de órgãos públicos ficou conhecida como New Public Management (NPM) ou Nova Gestão Pública (NGP). A Nova Gestão Pública enfoca o cidadão como sendo um cliente e tem como objetivo atender suas necessidades e expectativas.

Atualmente, existe a necessidade de integrar o cidadão ao processo decisório da administração pública, ou seja, no processo de decisão política. A contribuição dos cidadãos, representantes dos interesses locais, também denominados stakeholders, contribuem, de forma inovadora, para a solução de vários problemas enfrentados pelo governo. Segundo Freitas e Dacorso (2014), a Open Government Partnership - OGP, implementada desde 2011 no Brasil, representa o esforço governamental de utilizar práticas da administração privada na administração pública. Seus compromissos, dentre outros, é a aproximação da sociedade do processo decisório do governo, combater a corrupção, estimular a transparência e incentivar o uso de novas tecnologias. O governo brasileiro, signatário deste programa, criou um programa federal de acesso à informação visando estimular a transparência.

Criou, também, um banco único de dados que visa facilitar e otimizar o acesso às informações contidas no programa, empenhando-se concomitantemente em capacitar seus recursos humanos e aproximar-se, dessa forma, dos stakeholders. As ouvidorias representam, ainda, um canal que faz com que a sociedade seja capaz de se aproximar do governo, exprimindo, para tanto, as suas reclamações e sugestões. Este feedback dado pela sociedade a partir das ouvidorias proporciona que o governo busque o aprimoramento contínuo de seus serviços. A implementação de todas estas medidas e o investimento em tecnologia da informação capacitam o governo federal, o estadual, o distrito federal e o municipal a alcançar uma maior comunicação e eficiência na gestão pública. 


\subsection{ALGUNS DOS ATUAIS DESAFIOS ENFRENTADOS PELA GESTÃO PÚBLICA BRASILEIRA}

Diversos são os desafios enfrentados pela gestão pública brasileira. Pode-se mencionar a corrupção, a falta de transparência, o excesso de burocracia, a obsolescência das normas legais, a deficiente comunicação entre governo e sociedade, os escassos investimentos em ferramentas gerenciais e em tecnologia da informação, a desídia (desinteresse) por parte da sociedade em participar dos orçamentos participativos e a mão de obra estatal desmotivada e não qualificada.

\subsection{DESAFIOS E FERRAMENTAS DE GESTÃO}

São muitos, no cenário contemporâneo, os desafios enfrentados pelo setor público. Dentre eles destaca-se a adaptação às mudanças apresentadas no mundo atual, conferir maior agilidade aos processos licitatórios e ao gestor público, motivar os recursos humanos, buscar a melhoria contínua dos serviços estatais e implementar políticas públicas eficientes que atendam as expectativas dos clientes promovendo o bem-estar da sociedade. O governo federal, objetivando superar os desafios acima citados, implementou a Open Government Partnership - OGP, e, assim, adotou uma nova técnica de gestão denominada Nova Gestão Pública - NGP. O alinhamento do governo federal com a comunidade internacional para implantação da OGP aliado a utilização de ferramentas de gestão como a NGP, gestão de projetos e o investimento em sistemas informatizados capazes de consolidar informações gerenciais são instrumentos determinantes para superarmos os desafios atuais e edificar a nova gestão pública brasileira.

Paralelamente, é importante destacar que o investimento em qualificação profissional do servidor público, a profissionalização da gestão pública e a motivação da mão-deobra do estado são fatores que impactam na qualidade dos serviços prestados pelo Estado. Segundo Ferreira Júnior (2011), o investimento na profissionalização da gestão pública, focado nos resultados e metas, são fatores que influem, diretamente, na qualidade dos serviços públicos. Os fatores que motivam o ser humano são vários 
e intrínsecos. Não existe uma fórmula motivacional única e infalível. Cada indivíduo responde diferentemente a uma forma de incentivo. A motivação e a satisfação dos indivíduos estão intrinsecamente ligadas às suas necessidades. Entretanto, um fator motivacional importante a ser considerado é como as condições do trabalho são gerenciadas.

Há uma vertente de ideias relacionada ao que motiva o servidor público, são eles o salário, a gratificação e o prêmio em pecúnia vinculado ao desempenho do servidor. Segundo De Toni, deve-se adotar a uma nova realidade e a transparência de objetivos e metas institucionais. Brandão et al (2014) defendem que os fatores motivacionais que predominam na geração da satisfação dos funcionários públicos estão atrelados à realização profissional, às atividades desempenhadas e à responsabilidade atribuída. A motivação do servidor público pode ser uma mescla de tudo o que foi anteriormente abordado. Independentemente do fator preponderante responsável pela motivação do servidor, a sua participação é indispensável para a construção de um novo modelo de gestão. Cabe, aos governos, juntamente com o gestor público, o desenvolvimento de políticas e planos de carreira suscetíveis a desenvolver, motivar e valorizar seus recursos humanos.

Prado et al (2014) enfatizam que o fator motivador dos colaboradores será determinante na qualidade e excelência do serviço prestado. No mister de oferecer à sociedade um serviço público de qualidade, focado na economicidade dos recursos governamentais, surge a necessidade de modernizar a administração pública. Fazemse necessárias a revisão dos textos legais e a realização de investimentos em gestão de projetos e tecnologia da informação (TI). A gestão de projetos representa uma ferramenta de inestimável valia ao gestor e à administração pública. Segundo Furtado (2011), a gestão de projetos é uma prática emergente nas instituições governamentais. É um novo método de gestão no qual são definidas estratégias e metas.

O Brasil utiliza, predominantemente, o modelo de administração pública gerencial. Este método proporciona, aos gestores, maior autonomia em suas ações e considera os cidadãos como clientes. Utiliza-se de práticas gerenciais cujo foco está na 
descentralização, delegação de autoridade, planejamento, organização, eficácia, liderança e controle sobre o desempenho. A proposta dessa ferramenta gerencial é auxiliar o gestor público na tomada de decisões, dando ensejo à antecipação e saneamento de problemas. A gestão de projetos permite que os objetivos e metas traçados sejam alcançados de forma mais rápida, eficiente e com qualidade, e, também, proporciona à administração pública reduzir custos, tempo e oferecer à sociedade um serviço de maior qualidade.

Ziviani (2004) defende que existe uma mobilização global em prol da modernização da administração pública focada na eficiência, eficácia e agilidade. O advento da internet resultou na ampla divulgação da aplicação de recursos que favorece o controle e transparência dos gastos públicos. Nesse contexto, surgiu a Lei de Responsabilidade Fiscal. Ela representa um código de conduta para os gestores públicos. A Lei também preza pela modernização da administração, pelo equilíbrio e qualidade das finanças públicas. Ainda há um longo caminho a ser percorrido. É necessária uma mobilização para modernizar a legislação vigente, pois, ao gestor público, só é permitido fazer o que a lei permite, conforme o princípio da legalidade expresso no artigo 37 da Constituição Federal (MELLO, 2001).

Exemplificando, podemos citar a Lei 8.666/93. A lei regulamenta o art. 37, inciso XXI, da Constituição Federal e institui normas para licitações e contratos da administração pública. Segundo Xavier (2014), o coordenador geral de cadastro e licitação do DNIT afirmou que a legislação atual é muito formalista, tendo como consequência para a população o atraso na entrega do produto/serviço. Defende, ainda, que é necessário inovar no campo jurídico por meio da revisão do texto legal vigente. Afirmou, também, que a inovação seria necessária para que melhores práticas sejam incorporadas à administração pública, proporcionando, a ela, maior agilidade, além de simplificar o processo de licitação pública.

Silveira e Garcez (2002) defendem que um dos principais entraves na modernização da gestão é a carência de sistemas e métodos adequados empregados na consolidação de informações gerenciais. É necessário um esforço focado na capacitação, no fortalecimento institucional e na informatização. Segundo Rezende 
(2007), existem várias classificações para os sistemas de informação. Eles podem ser gerenciais, estratégicos, de manutenção ou adaptação, de desenvolvimento e aquisição. O sucesso desses sistemas depende do capital intelectual dos funcionários envolvidos e representará o fator determinante da qualidade dos serviços prestados pelo Estado.

O planejamento da informação, conhecimento e informática pela administração pública também pode ser chamado de Planejamento Estratégico da Tecnologia da Informação (PETI). Sua viabilização depende das informações coletadas, do emprego da tecnologia adequada e do comprometimento da mão-de-obra. Esse planejamento deve ser integrado e alinhado com os planejamentos estratégico, plurianual e plano diretor, pois são esses elementos que irão auxiliar o gestor público na tomada de decisões. Conforme Rezende (2007), o desenvolvimento de sistemas de informação focados na Gestão Pública resulta na obtenção de qualidade, de produtividade e de inteligência organizacional.

\subsection{ALGUMAS FERRAMENTAS DE GESTÃO}

Ferramentas de gestão representam recursos estratégicos que balizam as decisões dos gestores e impactam, diretamente, na qualidade e agilidade da gestão. Citaremos algumas dessas ferramentas, são elas: a técnica de gestão conhecida como Nova Gestão Pública (NGP); gestão de projetos; a internet e os sistemas informatizados capazes de consolidar informações gerenciais (podemos citar o SAP - software específico para gestão do setor público, ou o software IPM), dentre outros.

\subsection{A UTILIZAÇÃO DE FERRAMENTAS FOCADAS NA MELHORIA DA GESTÃO PÚBLICA NO BRASIL}

A fim de que a Gestão Pública brasileira evolua e se aprimore constantemente propomos a ampliação da utilização da Open Government Partnership - OGP, da internet e do orçamento participativo. O investimento maciço em sistemas informatizados capazes de consolidar informações gerenciais, ferramentas de gestão e qualificação e a modernização e motivação da mão de obra estatal é fundamental. 


\section{CONSIDERAÇÕES FINAIS}

Os desafios da gestão pública concentram-se prioritariamente em investimento em: ferramentas de gestão, em tecnologia da informação, na mão de obra estatal e na revisão/atualização dos textos legais. Dentre as perspectivas da Gestão Pública Brasileira está: o alinhamento com as tendências internacionais (OGP); o aprimoramento dos serviços oferecidos à população (NGP orçamento participativo); a adoção de novas técnicas (OGP) e novas técnicas de gestão (NGP/Gestão de Projetos/Tecnologia da Informação). Baseando-se no posicionamento atual do governo a tendência é que a Gestão Pública se torne mais ágil, eficiente e transparente. A análise do desenvolvimento da gestão nos proporciona compreender as dificuldades a serem superadas no presente e projetar o que queremos construir para o futuro.

Os desafios enfrentados pela gestão brasileira concentram-se em motivar/ qualificar a mão-de-obra estatal. Tal fato será o fator determinante da qualidade, agilidade e excelência do serviço prestado e dados coletados. Assim, os alocados na esfera moral devem ser saneados através da revisão/adequação dos textos legais à realidade do século XXI, os que dizem respeito a agilidade da máquina estatal propõem uma revisão da lei que rege os processos licitatórios e é pertinente que sejam feitos investimentos em ferramentas gerenciais. Tais ferramentas proporcionarão ao gestor público a consolidação de informações, o controle dos processos em andamento e agilidade no gerenciamento das informações da máquina pública proporcionando o desenvolvimento de políticas públicas que atendam as expectativas da sociedade.

Para que tal empreita tenha sucesso sugere-se a utilização das seguintes ferramentas de gestão: NGP; gestão de projetos; internet e sistemas informatizados capazes de consolidar informações gerenciais (TI). A melhoria da gestão pública no Brasil está atrelada a diversos fatores tais como à ampliação das ouvidorias, à capacitação da mão-de-obra, à ampliação da OGP, ao investimento em ferramentas gerenciais acima citadas e à vontade política. 


\section{REFERÊNCIAS}

BORDIN, L. B. Brasil começa a aderir ao formato digital de orçamento participativo. Vida Pública. 2014. Disponível em: http://www.gazetadopovo.com.br/vida-publica/brasil-comeca-a-aderir-ao-formatodigital-de-orcamento-participativo9q22n6g96sicmwhcf42nn0vny;jsessionid=5FE5E20199B273C6006585AC1382E2B7 . Acesso em: 21 fev. 2015.

BRANDÃO, I. de. F. et al. Satisfação no serviço público: um estudo na Superintendência Regional do Trabalho e Emprego no Ceará. REAd-Revista Eletrônica de Administração, v. 20, n. 1, p. 90-113, 2014.

BRASIL. TCM Investe Na Profissionalização Da Gestão Pública, Tribunal De Contas Municipal Do Pará. 2013. Disponível em: http://www.tcm.pa.gov.br/atuacaoe-competencia/681. Acesso em: 12 jul. 2015.

COSTA, D. M. D. Vinte anos de Orçamento Participativo: análise das experiências em municípios brasileiros. Cadernos Gestão Pública e Cidadania, v. 15, n. 56, p. 8-28, 2010.

DE TONI, J. Profissionalização da gestão pública e metodologia participativa. In: $\mathbf{X}$ Congreso Internacional del CLAD sobre la Reforma del Estado y de la Administración Pública, Santiago, Chile, 2005.

FERREIRA JÚNIOR, L. Profissionalização da Gestão Pública, CREA-SC. 2011. Disponível em: http://www.crea-sc.org.br/portal/index.php?cmd=artigosdetalhe\&id=1369\#.Vb00m_IVikp. Acesso em: 01 ago. 2015.

FILHO, L. M. A. Democracia no Orçamento Público: Orçamento Participativo. Disponível em: http://www.arcos.org.br/artigos/democracia-no-orcamento-publicoorcamento-participativo/. Acesso em 12 jul. 2015. 
FREITAS, R. K. V. de; DACORSO, A. L. R. Inovação aberta na gestão pública: análise do plano de ação brasileiro para a Open Government Partnership. Rev. Adm. Pública, v. 48, n. 4. jul/ago. 2014.

FURTADO, M. A. P. A Percepção dos Gestores da Área Pública sob a Política de Gerenciamento de Projetos. Revista Eletrônica Sistemas \& Gestão, v. 6, n. 2, p. 167-183, 2011.

GALHARDO, R. Assembleia paulista autoriza criação de conselhos populares. O Estado de S. Paulo, São Paulo, dezembro 2014. Disponível em: http://politica.estadao.com.br/noticias/geral,assembleia-paulista-autoriza-criacao-deconselhos-populares,1602204. Aceso em: 01 ago. 2015.

GARCEZ, A; SILVEIRA, J. P. Gestão pública orientada para resultados no Brasil. Revista do Serviço Público, Ano 53, n.4, out-dez. 2002.

MELLO, C. A. B. de. Curso de Direito Administrativo. 13ª ed. São Paulo: Malheiros, 2001.

PRADO, E. de. F. et al. Qualidade de Vida no Trabalho no Setor Público. In: Congresso Brasileiro de Engenharia de Produção, n. 4, 2014, Ponta Grossa, PR.

REZENDE, D. A. Planejamento de informações públicas municipais: sistemas de informação e de conhecimento, informática e governo eletrônico integrados aos planejamentos das prefeituras e municípios. Rev. Adm. Pública, v. 41, n. 3, p. 505536, 2007.

SILVA, G. G. da.; MENESES, P. P. M. Necessidades de treinamento organizacional e motivação para trabalhar. REAd. Rev. eletrôn. adm. (Porto Alegre), v. 18, n. 1, p. 2762, 2012.

XAVIER, L. G. Governo defende agilidade e simplificação dos processos de licitação pública. 2014. Disponível em: http://www2.camara.leg.br/camaranoticias/radio/materias/RADIOAGENCIA/486048- 
GOVERNO-DEFENDE-AGILIDADE-E-SIMPLIFICACAO-DOS-PROCESSO-DELICITACAO-PUBLICA.html. Acesso em: 09 Jul 2015.

ZIVIANI, J. Lei de Responsabilidade Fiscal. Revista Jus Navigandi, Ano 9, n. 517, 6 dez. 2004.

Enviado: Agosto, 2019.

Aprovado: Fevereiro, 2020. 